\title{
Correction to: Equivalent values between anterior vertebral height, wedge ratio, and wedge angle in osteoporotic vertebral fractures
}

\author{
Kozo Sato ${ }^{1} \cdot$ Masakazu Kogawa $^{1,2}$ (1) $\cdot$ Yuichiro Yamada $^{1} \cdot$ Masahiro Yamashiro $^{1} \cdot$ Fumio Kasama $^{1}$. \\ Michimasa Matsuda ${ }^{1}$
}

Published online: 30 September 2021

(c) The Japanese Society Bone and Mineral Research 2021

\section{Correction to: Journal of Bone and Mineral Metabolism https://doi.org/10.1007/s00774-021-01264-9}

In the original publication of the article, the last author "Michimasa Matsuda" was incorrectly tagged as corresponding author. The actual corresponding author is "Masakazu Kogawa".

The original article was updated.

Publisher's Note Springer Nature remains neutral with regard to jurisdictional claims in published maps and institutional affiliations.

The original article can be found online at https://doi.org/10.1007/ s00774-021-01264-9.

Masakazu Kogawa

m.kogawa@happy.email.ne.jp

1 Department of Orthopaedic Surgery, Matsuda Hospital, 17-1 Sanezawa aza Tatsutayashiki, Izumi-ku, Sendai, Miyagi 981-3217, Japan

2 Centre for Orthopaedic and Trauma Research, Discipline of Orthopaedics and Trauma, The University of Adelaide, North Terrace and George St., Adelaide, SA 5005, Australia 